\title{
Head and neck malignancies: Emerging concepts!
}

\section{Toran KC}

Associate Professor and HOD, Department of ENT-Head \& Neck Surgery, Kathmandu Medical College, Sinamangal, Nepal

$\mathrm{T}^{\mathrm{s}}$ he management of a patient with a head and neck malignancy demands a multi-disciplinary approach involving a variety of specialties. Although the main aim of management of such a patient is either to cure them or to prolong their survival with a good quality of life.

Both the newer radiological diagnostic capabilities, genomic and molecular concept of tumour behaviour, robotic surgery and improved optical technologies has added a new era in the management of such patient.

Researches on cancers are now more focused on the study biological/molecular behaviour and characteristics of the tumour. Over expression of the epidermal growth factor receptors (EGFR) by a tumour has a poor prognosis when treated with radiation alone ${ }^{1}$. For such tumour a targeted therapy with EGFR blocking antibodies such as tyrosin kinase inhibitors or Cetuximab will be more effective ${ }^{2}$. When all these conservative modalities fail to improve any tumours, they may then do well with surgeries. But still the region of the tumour involvement should be considered before advocating such treatment. Human papilloma virus-16 is also one of the causative factors for the oro-pharyngeal cancers with rather favourable prognosis both with surgery or radiotherapy alone ${ }^{3}$. The organ preservation approach, which incorporates combination of both chemotherapy and radiotherapy is being gradually adopted instead of radical surgery even for $T_{3}$ and resectable $T_{4}$ laryngeal and oro-pharyngeal cancers ${ }^{4}$. The effect of epigenetics, apoptosis ${ }^{5}$, demonstration of head and neck cancer stem cells and the role of chronic inflammation in cancer cells will definitely shed a paradigm shift in the cancer management. With all these newer advent the older and traditional anatomical staging of the head and neck tumours will soon be replaced by a more scientific biological staging. All the cancer treating surgeons and physicians need to rethink about the rapidly evolving theories on tumour behaviour and the limitations of conventional surgery, radiotherapy and chemotherapy.

All the above mentioned phrases doesn't mean that we all should engage ourselves to the expensive biological research, which is beyond the imagination of a poor country like ours, but we should at least keep ourselves updated to the rapidly changing trends in the management of head and neck cancers. All the clinicians interested in head and neck management, various clinical societies including the Cancer Relief Society of Nepal and even the international charitable organisations should come forward as a team to work on a rationalised basis of cancer management. This will be a very instrumental work in this field but sadly it is yet to be achieved. It is the time now that we all should prepare ourselves to tread on the path of effective head and neck cancer management.

\section{References}

1. Ang KK, Berkey BA, TU X et al. Impact of epidermal growth factor receptor expression on suvovap and pattern of relapse in patients with advanced head and neck carcinoma. Cancer Res. 2002;62(24):7350-6.

2. Bonner JA,Harari PM, Giralt . et al. Radiotherapy plus cetuximab for squamous cell carcinoma of head and neck. N Engl J Med 2006;354(6):56778.

3. Licitra L, Perrone F,Bossi P, et al. High risk human papilloma virus affects prognosis in patients with surgically treated oropharyngeal squamous cell carcinoma. J Clin Oncol. 2006;24(36):5630-6.

4. Urba SG,Moon J, Giri PGS, et al. Organ preservation for advanced respectable cancer of the base of the tongue and hypopharynx: a Southwest Oncology Group Trial. J Clin Oncol. 2005;23(1);88-95.

5. Kanazawa T, Kommareddi PK, Iwashita $\mathrm{T}$ et al. Galanin receptor subtype 2 supresses cell proliferation and induces apoptosis in P53 mutant Head and neck cells. Clin Cancer Research. 2009;15(7):2222-30. 